Coronary Artery Disease and Periodontal disease -Does severity correlates? An Angiographically confirmed cross-sectional study, Jaipur, India Vasim Raja Panwar ${ }^{1}$, Abhishek Sharma ${ }^{2}$, Shashi Mohan Sharma ${ }^{3}$, Sujal Parkar ${ }^{4}$, Setu Mathur ${ }^{5}$, Arvind Sharma ${ }^{6}$

${ }^{1}$ Associate Professor, Periodontics and Implantology, Rajasthan Dental College and Hospital, Jaipur; ${ }^{2}$ Assistant Professor, Public health dentistry. RUHS College of Dental Sciences (Government Dental College), Jaipur, Rajasthan, India; ${ }^{3}$ Senior Professor, Cardiology, SMS Hospital, Jaipur; ${ }^{4}$ Assistant Professor, Public health dentistry, Siddhpur dental college and hospital, Siddhpur, Patan, Gujarat. India; ${ }^{5}$ Assistant Professor, Periodontics, RUHS College of Dental Sciences, Jaipur, Rajasthan. India; ${ }^{6}$ Assistant Professor. Community and Family Medicine. RUHS College of Medical Sciences, Jaipur, Rajasthan

\begin{tabular}{|c|c|c|c|c|c|c|c|c|}
\hline Abstract & Introduction & Methodology & Results & Conclusion & References & Citation & \multicolumn{2}{|c|}{ Tables / Figures } \\
\hline \multicolumn{9}{|c|}{ Corresponding Author } \\
\hline \multicolumn{8}{|c|}{$\begin{array}{l}\text { Abhishek Sharma, Assistant Professor, Public health dentistry. RUHS College of Dental Sciences } \\
\text { (Government Dental College), Jaipur, Rajasthan, India } \\
\text { E Mail ID: } \underline{\text { drabhi712@gmail.com }}\end{array}$} & 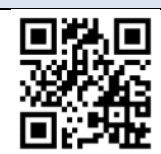 \\
\hline
\end{tabular}

\title{
Citation
}

Panwar VR, Sharma A, Sharma SM, Parkar S, Mathur S, Sharma A. Coronary Artery Disease and Periodontal disease -Does severity correlates? An Angiographically confirmed cross-sectional study, Jaipur, India. Indian J Comm Health. 2020;32(4):731-736. https://doi.org/10.47203/IJCH.2020.v32i04.021

Source of Funding: Nil Conflict of Interest: None declared

\section{Article Cycle}

Received: 26/09/2020; Revision: 11/11/2020; Accepted: 03/12/2020; Published: 31/12/2020 This work is licensed under a Creative Commons Attribution 4.0 International License.

\section{Abstract}

Background: Coronary artery disease is one of the leading causes of death worldwide. Chronic periodontal disease is the most common oral disease. Bacteremia associated with periodontal disease has an impact on vascular components and connective tissues, which in turn may play role in coronary artery disease. Aim: The aim of the study was to assess correlation between severity of coronary artery disease and periodontal disease. Material and methods: Severity of coronary artery disease was assessed by calculating Gensini scores from the coronary angiograms while periodontal status was assessed clinically by using community periodontal index (CPI) and loss of attachment index (LOA) as per WHO methodology 1997 among 700 participants. Results: The average Gensini score was reported as $30.54 \pm 22.84$. A significant correlation $(P<0.05)$ was found between Gensini score and CPI score 0, 2, 3 and 4. Conclusion: Weak correlation was found between severity of coronary artery disease and periodontitis.

\section{Keywords}

Coronary Artery Disease; Periodontitis; Angiogram; Cardiology

\section{Introduction}

Coronary artery disease (CAD) remain as one of the leading cause of death around the globe, despite of developing preventive and therapeutic advances. Chronic infectious and inflammatory diseases have been found as risk factor for coronary artery disease Hypertension, hyperlipidemia, diabetes mellitus, positive family history, habit of smoking are the major risk factors for $C A D$, which leads to premature death among adults. Atherosclerosis is the most common cause of CAD which results in acute myocardial infarction due to the plaque disruption with superimposed thrombus. (1)

All stages of CAD starting from plaque formation, plaque progress and ultimately plaque rupture have inflammatory processes underneath. Clinical picture 
of coronary artery disease, atherosclerosis includes angina, chest pain, myocardial infarction and ultimately death, are the outcomes of these inflammatory processes (2).

Periodontitis is sixth most common human disease worldwide. Periodontitis is usually associated with rise in biomarkers of chronic inflammation. Oral bacterial species related to periodontal disease can go into circulation and result in bacteremia. The endotoxins (Lipopolysaccharides) produced, can trigger the aggregation of plaque, resulting in formation of thrombi and atheroma plaque $(3,4)$. Prevalence of Non Communicable diseases (NCD) including periodontitis and cardiovascular disease is rising globally.

Outcome and fatality of atherosclerosis primarily depend upon extent and severity of CAD. Some angiographic tools/scoring systems have been proposed to quantify severity and complexity of coronary artery disease. Various studies (5-10) revealed a strong relationship between periodontitis and CAD, however few studies (11-13) shows no clear association between periodontitis and CAD. Along with, severity of coronary artery disease has not been taken into consideration in these studies, as assessed by coronary angiogram. There is a scarcity of evidence whether severity of CAD is associated with periodontitis or not.

\section{Aims \& Objectives}

To evaluate correlation between severity of coronary artery disease and periodontal disease.

\section{Material \& Methods}

Data collection: A cross-sectional study was carried out among 700 confirmed cases of CAD on angiogram in the Cardiology department, of one of the tertiary care hospital in city of Jaipur, India over a period of two years 2015 to 2017. Research protocol was submitted to institutional review board and ethical clearance was obtained to conduct the study. Participation was voluntary, and consent was obtained from all patients.

Both male and female patients were included in the study. Patients having co-morbidities like diabetes, liver disease and renal failure were excluded from the study. Those patients who underwent periodontal treatment within six months, current smokers, alcoholics were also excluded from the study.

Coronary artery disease severity assessment: Severity of CAD was assessed by calculating Gensini scores from the coronary angiograms. Gensini scoring system is commonly used in cardiology for quantifying severity and complexity of atherosclerosis. Gensini scores were calculated with help of experienced cardiologists. Gensini score calculation makes use of three different characteristics of each coronary artery lesion as degree of stenosis, a weighting factor that assign to importance of a lesion in segment, and collateral adjustment factor. Fourteen segments represent coronary arterial tree on angiogram. Severity of atherosclerosis is indicated by Gensini score, as high the score so the extent and severity of coronary stenosis will be.

Periodontal assessment: The periodontal status was assessed using Community Periodontal Index (CPI) and Loss of Attachment (LOA) index, as per WHO methodology 1997 (14) (Table 1) Principal investigator recorded periodontal status and a trained recorder enumerated in designated proforma.

Statistical analysis: Mean scores were compared by using one way ANOVA test. The proportions were compared by using chi square test. To determine correlation between the severity of CAD and periodontitis, Spearman correlation test was applied. The Gensini scores were dichotomized as score $<60$ no disease and $>60$ having disease. The multivariable dependence of Gensini score on categorical variables (age, gender and periodontal disease $<4 \mathrm{~mm}$ and $>4 \mathrm{~mm}$, hypertension) was analyzed using logistic regression with entre method. Adjusted odds ratio (OR) with a 95\% confidence interval $(\mathrm{Cl})$ of risk of Gensini score were calculated. Statistical Package for Social Science (SPSS version 22, IBM cooperation). Level of significance was kept as $\mathrm{P}<0.05$.

\section{Results}

Out of 700 patients, 496 (70.8\%) were males and 204 $(29.2 \%)$ females. The age ranges from $36-68$ years having mean age of $58.9 \pm 7.30$ years. Gensini score were found in the range from 2 to 120 among the participants having mean score of $30.54 \pm 22.84$. The mean sextant scores for CPI and LOA were compared age wise in (Table 2).

No statistically significant difference $(P>0.05)$ was found between mean scores of CPI and LOA age wise. (Table 3) shows correlation between Gensini score and CPI and LOA score (periodontal parameters). Spearman correlation coefficient shows week 

correlation between Gensini score and CPI score ranging from -0.17 to 0.15 . The correlation was highly statistically significant $(P<0.001)$ between Gensini score and CPI score 0, 2, 3, and 4. Spearman correlation coefficient were too week between Gensini score and LOA score which was not significant statistically ( $P>0.05)$.

Multiple logistic regression analysis, as presented in (Table 4) demonstrates risk factors related with severity of coronary artery disease (Gensini score). Males (OR=1.03), advanced age $(\mathrm{OR}=8.18)$ and periodontal diseases $(\mathrm{CPI}>3)(\mathrm{OR}=1.50)$ were at greater risk for CAD.

\section{Discussion}

Globally cardiovascular diseases rank the top most disease resulting in premature death. Hence, becomes of utmost importance to understand its clinical and epidemiological perspective. Various studies have been conducted relating cardiovascular diseases and periodontal disease, but no concrete conclusions have been found. Some systematic reviews and meta-analysis of these relating diseases concluded a minor role of periodontal disease associated with coronary artery disease. In contrast, some studies have observed definite correlation between coronary artery diseases and periodontal disease $(2,4,5$, and 15$)$.

Our results are similar to the findings of the study conducted by Fadel HT et al (16), in which they found severe periodontal disease in patients with CAD. Similarly Geerts SO et al (17) observed that periodontal disease was more common among CAD patients as compared with controls. Various biological plausibility routes have been postulated to show the correlation between periodontal disease and CAD. Periodontal disease process involves a chronic condition with inflammatory process, which results into increased levels of inflammatory markers like $C$ reactive protein and serum interleukin (IL6)., Conversely, there is decrease in levels of inflammatory markers following periodontal therapy has also been reported. (18-20).

Some studies reported intermittent bacteremia consecutive with periodontal disease process, the other concept for the association with CAD. Bactermia play a role in inflammation process or can directly affect endothelial tissue surfaces (21). An association was observed between calcification of coronary artery and periodontal diseases in a part of ARIC study. (22)
Enhanced activation of platelets in vivo in conjugation with periodontal disease might result in instable plaque and ultimately thrombus formation (23). Periodontal disease has also been suggested as a risk factor for stroke as well as carotid atherosclerosis. An association was found for increased risk of stroke among patients with periodontal disease. Likewise, link was observed between tooth loss due to periodontal disease and peripheral valvular disease. Results of study conducted by Mattila KJ et al (24) support the role of periodontal disease in atheromatosis and are in accordance with the result of the present study.

On the contrary, Bazile A et al (25) found no significant associations between probing depth and CAD. In accordance with our results, studies conducted by Mattila KJ et al (26), Persson RG et al (27), Pearson TA et al (28) have shown a correlation between CAD and periodontal disease.

We found statistically significant correlation between Gensini scores and highest CPI scores. This was in accordance with study conducted by Yang et al (29), but the process for the same is unclear and there may a nexus of various factors affecting both the diseases. Parkar SM et al (30) found that patients with myocardial infarction can demonstrate severe periodontal disease. They also found association between myocardial infarction and chronic periodontal disease. (31)

Limitations of this study include, the present study was cross-sectional study design, and so only correlation has been found and reported. This present study is not able to show causation or biological plausibility. Various confounding factors such as geographic location, socioeconomic status, dietary pattern and immune compromised conditions must be taken into account. If a clear relation and biological plausibility with direction of disease can be established, it could help health care workers to combat deadly cardiovascular diseases. Establishing relation between these two conditions will also enable oral health care professionals to treat periodontal disease patients comprehensively. By observing and assessing patient periodontal conditions, risk for coronary artery disease can be predicted and they can be taken care on appropriate time.

\section{Conclusion}

Within the limitations of the study, following conclusions were drawn from the results - There was 
a correlation between periodontitis and severity of CAD but the correlation was weak. However, to support this result, longitudinal study needs to be conducted. Findings from these studies might help prediction of CAD; its severity based on periodontal examination and in turn would be helpful to reduce mortality of coronary atherosclerosis.

\section{References}

1. Najafi-Parizi G, Lori A. Periodontal Disease as a Risk Factor for Coronary Artery Disease. Am J Appl Sci. 2005;2 (11): 1526-1528

2. Mahendra J, Mahendra L, Kurian VM, Jaishankar K, Mythilli R. Prevalence of periodontal pathogens in coronary atherosclerotic plaque of patients undergoing coronary artery bypass graft surgery. J Maxillofac Oral Surg. 2009;8(2):108-13. doi: 10.1007/s12663-009-0028-5. Epub 2009 Aug 11. PMID: 23139486; PMCID: PMC3453943.[PubMed]

3. Barilli AL, Passos AD, Marin-Neto JA, Franco L. Periodontal disease inpatients with ischemic coronary atherosclerosis at a University Hospital. ArqBras Cardiol. 2006;87(6):695700. English, Portuguese. doi:10.1590/s0066782x2006001900003. PMID: 17262105.[PubMed]

4. Armitage GC. Periodontal infections and cardiovascular disease--how strong isthe association? Oral Dis. 2000;6(6):335-50. doi:10.1111/j.16010825.2000.tb00126.x. PMID: 11355266.[PubMe].

5. Armitage GC. Periodontal infections and cardiovascular disease--how strong isthe association? Oral Dis. 2000;6(6):335-50. doi:10.1111/j.16010825.2000.tb00126.x. PMID: 11355266.[PubMed]

6. Ebersole JL, Machen RL, Steffen MJ, Willmann DE. Systemic acute-phase reactants, C-reactive protein and haptoglobin, in adult periodontitis. Clin Exp Immunol. 1997;107(2):34752. doi: 10.1111/j.1365-2249.1997.270-ce1162.x. PMID: 9030874; PMCID: PMC1904587.[PubMed].

7. Kweider M, Lowe GD, Murray GD, Kinane DF, McGowan DA. Dental disease, fibrinogen and white cell count; links with myocardial infarction? Scott Med J. 1993;38(3):73-4. doi: 10.1177/003693309303800304.

PMID: 8356427.[PubMed].

8. Noack B, Genco RJ, Trevisan M, Grossi S, Zambon JJ, De Nardin E. Periodontal infections contribute to elevated systemic C-reactive protein level. J Periodontol. 2001;72(9):1221-7. doi: 10.1902/jop.2000.72.9.1221. PMID: 11577954.[PubMed]

9. Slade GD, Offenbacher S, Beck JD, Heiss G, Pankow JS. Acute-phase inflammatory response to periodontal disease in the US population. J Dent Res. 2000;79(1):49-57. doi: 10.1177/00220345000790010701. PMID: 10690660.[PubMed]

10. Wu T, Trevisan M, Genco RJ, Falkner KL, Dorn JP, Sempos $\mathrm{CT}$. Examination of the relation between periodontal health status and cardiovascular risk factors: serum total and high density lipoprotein cholesterol, C-reactive protein, and plasma fibrinogen. Am J Epidemiol. 2000;151(3):273-82. doi: 10.1093/oxfordjournals.aje.a010203. PMID: 10670552.[PubMed]

11. Hujoel PP, Drangsholt M, Spiekerman C, Derouen TA. Examining the link between coronary heart disease and the
[Coronary Artery Disease...] | Panwar VR et al elimination of chronic dental infections. J Am Dent Assoc. 2001;132(7):883-9. doi: 10.14219/jada.archive.2001.0300. PMID: 11480641.[PubMed].

12. Howell TH, Ridker PM, Ajani UA, Hennekens $\mathrm{CH}$, Christen WG. Periodontal disease and risk of subsequent cardiovascular disease in U.S. male physicians. J Am Coll Cardiol. 2001;37(2):445-50. doi: 10.1016/s07351097(00)01130-x. PMID: 11216961.[PubMed].

13. Tuominen R, Reunanen A, Paunio M, Paunio I, Aromaa A. Oral health indicators poorly predict coronary heart disease deaths. J Dent Res. 2003;82(9):713-8. doi: 10.1177/154405910308200911. PMID: 12939356.[PubMed]

14. Oral health survey basic methods. World Health Organization, Geneva. 4th ed. Delhi: AITBS Publisher and Distributors; 1997. p. 16-20

15. 1: Humphrey LL, Fu R, Buckley DI, Freeman M, Helfand M. Periodontal disease and coronary heart disease incidence: a systematic review and meta-analysis. J Gen Intern Med. 2008;23(12):2079-86. doi: 10.1007/s11606-008-0787-6. Epub 2008 Sep 20. PMID: 18807098; PMCID: PMC2596495.[PubMed].

16. Fadel HT, Al-Kindy KA, Mosalli M, Heijl L, Birkhed D. Caries risk and periodontitis in patients with coronary artery disease. J Periodontol. 2011;82(9):1295-303. doi: 10.1902/jop.2011.100655. Epub 2011 Feb 2. PMID: 21284544. [PubMed]

17. Geerts SO, Legrand V, Charpentier J, Albert A, Rompen EH. Further evidence of the association between periodontal conditions and coronary artery disease. J Periodontol. 2004;75(9):1274-80. doi: 10.1902/jop.2004.75.9.1274. PMID: 15515345.[PubMed].

18. Glurich I, Grossi S, Albini B, Ho A, Shah R, Zeid M, Baumann $\mathrm{H}$, Genco RJ, De Nardin E. Systemic inflammation in cardiovascular and periodontal disease: comparative study. Clin Diagn Lab Immunol. 2002;9(2):425-32. doi: 10.1128/cdli.9.2.425-432.2002. PMID: 11874889; PMCID: PMC119918. [PubMed]

19. Joshipura KJ, Wand HC, Merchant AT, Rimm EB. Periodontal disease and biomarkers related to cardiovascular disease. J Dent Res. 2004;83(2):151-5. doi: 10.1177/154405910408300213. PMID: 14742654.[PubMed].

20. Sahingur SE, Sharma A, Genco RJ, De Nardin E. Association of increased levels of fibrinogen and the $-455 \mathrm{G} / \mathrm{A}$ fibrinogen gene polymorphism with chronic periodontitis. J Periodontol. 2003;74(3):329-37. doi: 10.1902/jop.2003.74.3.329. PMID: 12710752.[PubMed]

21. Haraszthy VI, Zambon JJ, Trevisan M, Zeid M, Genco RJ. Identification of periodontal pathogens in atheromatous plaques. J Periodontol. 2000;71(10):1554-60. doi: 10.1902/jop.2000.71.10.1554. PMID: 11063387.[PubMed]

22. Desvarieux M, Demmer RT, Rundek T, Boden-Albala B, Jacobs Jr D, Papapanou PN et al. Relationship between periodontal disease, tooth loss, and carotid artery plaque: the Oral Infections and Vascular Disease Epidemiology Study (INVEST). Stroke. 2003;34(9):2120-5

23. Sharma A, Novak EK, Sojar HT, Swank RT, Kuramitsu HK, Genco RJ. Porphyromonas gingivalis platelet aggregation activity: outer membrane vesicles are potent activators of murine platelets. Oral Microbiol Immunol. 2000;15(6):393- 
6. doi: 10.1034/j.1399-302x.2000.150610.x. PMID: 11154438. [PubMed]

24. Mattila KJ, Valle MS, Nieminen MS, Valtonen VV, Hietaniemi KL. Dental infections and coronary atherosclerosis. Atherosclerosis. 1993;103(2):205-11. doi: 10.1016/00219150(93)90263-t. PMID: 8292096.[PubMed]

25. Bazile A, Bissada NF, Nair R, Siegel BP. Periodontal assessment of patients undergoing angioplasty for treatment of coronary artery disease. J Periodontol. 2002;73(6):631-6. doi: 10.1902/jop.2002.73.6.631. PMID: 12083536.[PubMed]

26. Mattila KJ, Nieminen MS, Valtonen VV, Rasi VP, Kesäniemi YA, Syrjälä SL, Jungell PS, Isoluoma M, Hietaniemi K, Jokinen MJ. Association between dental health and acute myocardial infarction. BMJ. 1989;298(6676):779-81. doi: 10.1136/bmj.298.6676.779. PMID: 2496855; PMCID: PMC1836063.[PubMed].

27. Rutger Persson G, Ohlsson O, Pettersson T, Renvert S. Chronic periodontitis, a significant relationship with acute myocardial infarction. Eur Heart J. 2003;24(23):2108-15. doi: 10.1016/j.ehj.2003.10.007. PMID: 14643271.[PubMed].

28. Pearson TA, Mensah GA, Alexander RW, Anderson JL, Cannon RO, Criqui $M$ et al. Markers of inflammation and
[Coronary Artery Disease...] | Panwar VR et al cardiovascular disease: application to clinical and public health practice: a statement for healthcare professionals from the Centers for Disease Control and Prevention and the American Heart Association. Circulation. 2003;107(3):499-511.

29. Yang J, Feng L, Ren J, Wu G, Chen S, Zhou Q, Du Z, Zhang S, $\mathrm{Hu} C$, Wu $X$, Ling L. Correlation between the severity of periodontitis and coronary artery stenosis in a Chinese population. Aust Dent J. 2013;58(3):333-8. doi: 10.1111/adj.12087. Epub 2013 Jul 31. PMID: 23981215.[PubMed]

30. Parkar SM, Modi GN, Jani J. Periodontitis as risk factor for acute myocardial infarction: A case control study. Heart Views. 2013;14(1):5-11. doi: 10.4103/1995-705X.107113. PMID: 23580918; PMCID: PMC3621229.[PubMed]

31. Sanz M, Marco Del Castillo A, Jepsen $S$, Gonzalez-Juanatey JR, D'Aiuto F, Bouchard P, Chapple I, Dietrich T, Gotsman I, Graziani F, Herrera D, Loos B, Madianos P, Michel JB, Perel P, Pieske B, Shapira L, Shechter M, Tonetti M, Vlachopoulos C, Wimmer G. Periodontitis and cardiovascular diseases: Consensus report. J Clin Periodontol. 2020;47(3):268-288. doi: 10.1111/jcpe.13189. Epub 2020 Feb 3. PMID: 32011025; PMCID: PMC7027895.[PubMed].

\section{Tables}

TABLE 1 COMMUNITY PERIODONTAL INDEX (CPI) AND LOSS OF ATTACHMENT INDEX (LOA)

\begin{tabular}{|c|c|}
\hline \multicolumn{2}{|c|}{ Community Periodontal Index (CPI) } \\
\hline Code 0 & Healthy \\
\hline Code 1 & Bleeding observed, directly or by using a mouth mirror, after probing \\
\hline Code 2 & Calculus detected during probing, but all of the black band on the probe visible \\
\hline Code 3 & Pocket 4-5 mm in depth (gingival margin situated on black band on the probe) \\
\hline Code 4 & Pocket $6 \mathrm{~mm}$ or more (black band of the probe not visible) \\
\hline Code $\mathrm{X}$ & Excluded sextant (less than two teeth present) \\
\hline \multicolumn{2}{|c|}{ Loss of Attachment Index (LOA) } \\
\hline Code 0 & $\begin{array}{l}\text { LOA 0-3 mm (CEJ not visible and CPI score 0-3) If the CEJ is not visible and the CPI score is } 4 \text { or if the CEJ is } \\
\text { visible }\end{array}$ \\
\hline Code 1 & LOA 4-5 mm (CEJ within black band) \\
\hline Code 2 & LOA 6-8 mm (CEJ between upper limit of black band and $8.5 \mathrm{~mm}$ ring) \\
\hline Code 3 & LOA 9-11 mm (CEJ between 8.5 and $11.5 \mathrm{~mm}$ rings) \\
\hline Code 4 & LOA $12 \mathrm{~mm}$ or more (CEJ beyond $11.5 \mathrm{~mm}$ ring) \\
\hline Code X & Excluded sextant (less than two teeth present) \\
\hline
\end{tabular}

TABLE 2 AGE WISE COMPARISON OF MEAN SEXTANT SCORES FOR COMMUNITY PERIODONTAL INDEX (CPI) AND LOSS OF ATTACHMENT INDEX (LOA)

\begin{tabular}{|c|c|c|c|c|c|}
\hline $\begin{array}{l}\text { Age Groups } \\
\text { (Years) }\end{array}$ & CPI 0 & CPI 1 & CPI 2 & CPI 3 & CPI 4 \\
\hline $36-45$ & $2.63 \pm 2.66$ & $0.47 \pm 1.22$ & $1.93 \pm 1.86$ & $0.57 \pm 0.89$ & $0.40 \pm 0.77$ \\
\hline $46-55$ & $2.35 \pm 2.54$ & $0.81 \pm 1.76$ & $1.54 \pm 1.97$ & $0.77 \pm 1.35$ & $0.53 \pm 1.16$ \\
\hline $56-65$ & $2.34 \pm 2.59$ & $0.54 \pm 1.37$ & $1.80 \pm 2.08$ & $0.66 \pm 1.19$ & $0.66 \pm 1.29$ \\
\hline$>65$ & $2.09 \pm 2.58$ & $0.66 \pm 1.44$ & $2.24 \pm 2.27$ & $0.52 \pm 0.97$ & $0.49 \pm 1.23$ \\
\hline P Value & 0.67 & 0.31 & 0.06 & 0.37 & 0.40 \\
\hline Age Groups (Years) & LOA 0 & LOA 1 & LOA 2 & LOA 3 & LOA 4 \\
\hline $36-45$ & $5.13 \pm 1.50$ & $0.67 \pm 1.24$ & $0.10 \pm 0.31$ & 0 & $0.07 \pm 0.37$ \\
\hline $46-55$ & $4.99 \pm 2.01$ & $0.53 \pm 1.42$ & $0.30 \pm 0.77$ & $0.11 \pm 0.46$ & $0.05 \pm 0.25$ \\
\hline $56-65$ & $4.76 \pm 2.14$ & $0.68 \pm 1.53$ & $0.34 \pm 1.01$ & $0.07 \pm 0.38$ & $0.02 \pm 0.17$ \\
\hline$>65$ & $4.59 \pm 2.20$ & $0.58 \pm 1.35$ & $0.48 \pm 1.20$ & $0.14 \pm 0.55$ & $0.04 \pm 0.23$ \\
\hline
\end{tabular}


Data presented as Mean \pm standard deviation. Mean value is compared by using one way ANOVA test. P $>0.05$ not significant

\section{TABLE 3 CORRELATION BETWEEN CPI, LOA AND GENSINI SCORE}

\begin{tabular}{|c|c|c|c|c|c|c|}
\hline \multirow{6}{*}{ Gensini score } & CPI & CPI 0 & CPI 1 & CPI 2 & CPI 3 & CPI 4 \\
\hline & Correlation Coefficient & $-0.17^{* *}$ & -0.02 & $0.15^{* *}$ & $0.11^{* *}$ & $0.11^{* *}$ \\
\hline & p-value & 0.002 & 0.54 & 0.002 & 0.002 & 0.002 \\
\hline & LOA & LOA 0 & LOA 1 & LOA 2 & LOA 3 & LOA 4 \\
\hline & Correlation Coefficient & -0.01 & 0.01 & 0.02 & -0.02 & -0.01 \\
\hline & $p$-value & 0.86 & 0.80 & 0.49 & 0.46 & 0.79 \\
\hline
\end{tabular}

TABLE 4 MULTIPLE LOGISTIC REGRESSION ANALYSIS FOR THE RISK FACTORS OF GENSINI SCORE

\begin{tabular}{|c|c|c|c|c|c|}
\hline Variables & [?]coefficient & Standard error & Odd ratio & $95 \% \mathrm{Cl}$ & $P$ value \\
\hline Gender (Male) & 0.03 & 0.17 & 1.03 & $0.74-1.45$ & 0.84 \\
\hline Age groups & & & & & $<0.001^{* *}$ \\
\hline $46-55$ & 1.27 & 0.58 & 3.57 & $1.15-11.02$ & $0.03 *$ \\
\hline $56-65$ & 1.86 & 0.55 & 6.45 & $2.20-18.88$ & $0.001^{*}$ \\
\hline$>65$ & 2.10 & 0.57 & 8.18 & $2.69-24.86$ & $<0.001^{* *}$ \\
\hline Periodontal disease (CPI>3) & 0.41 & 0.16 & 1.50 & $1.11-2.04$ & $0.01 *$ \\
\hline Constant & -2.11 & 0.55 & 0.12 & & $<0.001^{* *}$ \\
\hline
\end{tabular}

